\title{
A Study on the Effectiveness of Tour Guides Training Programs in Iran-Tehran
}

\author{
Kamran Mohamadkhani \\ Department of Higher Education Administration \\ School of Management and Economics, Science and Research Branch \\ Islamic Azad University (IAU), Tehran, Iran \\ Minoo Ashrafi \\ City Training Institute (CTI) \\ Cultural \& Artistic Organization for Tehran Municipality Tehran, Iran
}

Received: January 22, 2013 Accepted: February 5, 2012

doi:10.5296/ber.v3i1.3289 URL: http://dx.doi.org/10.5296/ber.v3i1.3289

\begin{abstract}
This study was conducted to evaluate the effectiveness of tour guides training programs of Tehran. The research Method applied in the study was descriptive in terms of data collection method, and practical in terms of the purpose of the study. The population was composed of both tour guides training course learners and travel agency managers in Tehran $(\mathrm{N}=545)$. Sampling in this study was stratified random and the sample size was calculated based on Krejcie - Morgan Table $(\mathrm{n}=166)$. The data gathering instruments were two researcher-administered questionnaires based on Kirkpatrick's model. The first questionnaire consisted of three indicators of attitude (reaction), learning and behavior and answered by learners and the second questionnaire contained questions that evaluated two components of behavior and the results and was filled out by the travel agency managers. The Questionnaires' validity were determined through the judgment of 10 tourism training experts and university professors and the reliability was assessed by Cronbach's alpha coefficient $(\alpha=$ 0.79). In analyzing the data, in order to compare the experimental and theoretical mean, single-group $\mathrm{T}$ test was used and the results indicated that among five sub-hypotheses which had been derived from the main research hypothesis, the means of four hypotheses were significantly higher than the theoretical mean, suggesting the effectiveness of the overall
\end{abstract}


training courses. The fifth hypothesis in which the difference between the acquired mean and theoretical mean was significant, was very small and negligible, in other words, it could be concluded with $95 \%$ confidence that tour guides training program in Tehran was effective.

Keywords: Tour guide, training programs, effectiveness, Kirkpatrick's evaluation model

\section{Introduction}

Tourism as one of the world's five major industries has been in development in recent years, overtaking other industries, according to reports announced by the World Tourism Organization (WTO, 2011). Despite the huge challenges raised in the development of the tourism, this industry has experienced a $4.5 \%$ growth compared to its previous year. Arrival of international tourists at tourism destinations will approximately reach one billion by the end of 2013 and the revenues thereof will hit 2 trillion dollars, however, unfortunately, in spite of enjoying numerous cultural, social and natural attractions, Iranian tourism industry has not been able to achieve its rightful place. Besides the reasons that can be cited for this problem, without a doubt, lack of skillful and trained manpower plays a critical role in the regression of tourism industry arena in Iran. The success of tour guides as the most influential players in mass tourism stage (Mohamadkhani, 2008) requires expertise and a skill set of capabilities that are not feasible in the absence of professional training. In case the training leads to performance promotion, the organizational effectiveness will evolve. This study can provide useful information to managers who can make the decisions "based on their design, implementation and evaluation of in-service programs" (Soltani, 2003). Although tourism activities and trainings have recorded a 2- decade history, the effectiveness of these programs in Iran has never been studied and analyzed. Tour guides training which is being executed by private institutions and under the supervision of the Tourism Department of the Cultural Heritage, Tourism and Handicrafts Organization, like any other training programs needs to be assessed in terms of its quality and effectiveness, so that the feedback required to improve and modify the program provided. In addition, the results of this study could help organizations, public institutions and policy makers improve the quality of tourism education, resulting in the enhancement of tour guides' quality of performance.

The present study is an attempt to evaluate the effectiveness of tour guides training program in Tehran in four levels of reaction, learning, behavior, and results via employing Kirkpatrick evaluation model, as one of the most practical and compatible models in this regard (Abbasain, 2006).

\section{Literature Review}

Nowadays, human resources training in organizations is known as one of the requirements for success and service quality maintenance. Being aware of the learning process and how it affects employee's behavior is critical and of paramount importance as a lot of organizations spend significant amounts of money to train their employees.

Weaknesses that can be seen in many executive management systems is due to the fact that Managers and supervisors are not considerate enough to train staff and eventually do not get appropriate feedbacks (Stewart et al, 2003). Tourist centers and agencies as domestic and 
international tour organizers can record effective measures and present the desired services in case they enjoy qualified and trained manpower, meanwhile, the tour guides who are indeed the real ambassadors of their countries, by performing their duties properly and playing a vital role can take the significant steps to the satisfaction of international tourism (Mohamad khani, 2008). Performing the duties properly cannot be achieved, unless they enjoy a set of capabilities which can be obtained by learning and training (Prakash, et al, 2010). Training in the tourism industry is considered as the inherent nature of this industry and life and death of tourism depends on training (Bushwell, et al. 2003), but whether the training held in tourism has been successful in realizing the desired goals or not (Alajlvny et al, 2010) lies among those important issues that estimates the necessity of evaluating the effectiveness of training for tour guides. Assessing the effectiveness of training means to determine to what extent the undertaken training has led to acquire the required practical skills. In other words, evaluating the effectiveness of training means:

- Determining the realization of educational objectives.

- Determining the visible results of apprentices in training run

- Determining the apprentices' behavior compliance with the expectations of institutional role.

- Determining to what extent, the accomplished task is in accordance with the task considered by organization

- Determining the Created abilities obtained by training to achieve the aims of education

- Determining the value added as the quality and the value which is added to the education system

- The extent to which it can be feasible to attribute learners' and apprentices' present status in terms of knowledge, attitude, and skills to educational system, meanwhile, is considered as quality value (Bazargan, 1983, p 129).

The other approaches and models found in assessing the effectiveness of training could be Askryvn approach (1987), Papham approach, Septet Pattern of Center for Assessment Studies (CIPP), IPOO evaluation pattern, Sullivan's evaluating pattern, Traveling Validation System (TVS) evaluation pattern (accreditation), Kirkpatrick's evaluation model and the evaluation model of Phillips (return on investment ROI). In this study, Kirkpatrick's evaluation model was used to evaluate the effectiveness of tourist guides' training programs .

Kirkpatrick's evaluation model to evaluate human resource management is one of the most effective models (Chang et al, 2010). The model is used to evaluate the effectiveness of training period, introducing four levels or four requirements as follows:

A) Reaction: At this level learners will be asked to reveal their reactions (attitudes) about the training programs they have gone through.

B) Learning (knowledge): At this level, learners indicate their assessing about learning levels (knowledge) obtained. 


\section{MInstitute Macrothink}

Business and Economic Research

ISSN 2162-4860

2013, Vol. 3, No. 1

C) Behavior: At this level, the changes emerged in behavior of participants during the training courses will be evaluated.

D) Results: At this level, the realization of goals directly related to the pervasive work place is evaluated. Since at this level topics such as: cost reduction, over doings, increasing the quality of products and services, and sales and profits are examined, it is very difficult to measure the results.

The following reasons assert why Patrick's model takes priority over the other models: Firstly, this model is used to assess the effectiveness of those jobs that require training; Secondly, its implementation can be done in a systematic manner; Thirdly, the emphasis in this model is on the fourth level results, and it can certainly contain a great deal of information for researchers and evaluators of training courses.

Since the training of tour guides should be fully functional and service-oriented, and analyzing the employers' perspective in this industry is very impressive, therefore, in order to evaluate the effectiveness of tour guides training courses in Tehran, Kirkpatrick's model was used.

\section{Research questions}

In order to achieve the objectives of the study, a main research question and four subsidiary questions were formulated as follow:

\section{Main Research question}

How effective are the tour guides training programs in Tehran?

\section{Sub-questions}

1. To what extend were the tour guides training courses in Tehran effective in terms of learner's attitude (reaction)?

2. To what extend were the tour guides training courses in Tehran effective in terms of learners' learning (knowledge)?

3. To what extend were the tour guides training courses in Tehran effective In terms of changing learners' behavior?

4. To what extend were the tour guides training courses in Tehran effective in changing learners' behavior from the perspective of employers?

\section{Research Method}

The present study aimed at evaluating the effectiveness of tour guides training programs in the Iranian context and its findings can be applied and considered in policy making programs of country's tourism organization. It can hence be considered an applied research. On the other hand, since this study sought to examine and describe the effectiveness of training courses, it can be classified into descriptive research category.

The population of the study included learners in tour guides educational institutions in Tehran dealing with program during the year 2012. These institutions are running under the 
supervision of the Tourism Department of the Cultural Heritage, Tourism and Handicrafts Organization. 545 trainees $(\mathrm{N}=545)$ therefore formed the general population of the study. In addition, managers of travel agencies as well as employers took part in the study.

Sampling method in this research was stratified random and the sorting criterion was educational centers providing tour guides training courses. The sample size was calculated based on Krejcie - Morgan Table $(n=166)$.

Table 1. Educational Centers, Population and Sample Sizes

\begin{tabular}{|c|c|c|c|}
\hline Educational Center & Number of Trainees (Population) & Percent & Sample Size \\
\hline Trasheh Tasvir & 35 & $42.6 \%$ & 10 \\
\hline Avaye Tabiat & 101 & $53.18 \%$ & 31 \\
\hline Ataland & 97 & $79.17 \%$ & 30 \\
\hline Avaye Jalbe Sayahan (No,1) & 131 & $24 \%$ & 40 \\
\hline Avaye Jalbe Sayahan (No,2) & 58 & $64.10 \%$ & 18 \\
\hline Ifachikar & 123 & $56.22 \%$ & 37 \\
\hline Total & 545 & 100 & 166 \\
\hline
\end{tabular}

Data gathering instruments in this research were two sets of questionnaires: The first questionnaire consisted of questions evaluating three levels of reaction, learning and behavior that were answered by learners and the second contained questions that evaluated two components of behavior and results and were filled out by the travel agency managers. Both questionnaires contained information on the purpose of the investigation and how to respond to the questions. Furthermore, individual characteristics and demographic data were collected. The constitutional components of the questionnaires were as follows:

Table 2. Item distribution based on the components

\begin{tabular}{|c|c|c|}
\hline Row & Components (evaluation levels) & Item numbers in the questionnaires \\
\hline 1 & Reaction & $1-18$ (level 1) \\
\hline 2 & Learning & $1-17$ (level 2) \\
\hline 3 & Behavior (trainees' perspective) & $1-6$ (level 3) \\
\hline 4 & Behavior (employers' perspective) & $1-6$ (level 3) \\
\hline 5 & Results (employers' perspective) & $1-6$ (level 4) \\
\hline
\end{tabular}

Content validity was applied to determine the validity of the questionnaires. Thus the initial questionnaires administered were judged by 10 tourism training experts and university professors and the modifications were made to present the final questionnaires to be implemented. In order to determine the reliability of the questionnaires, Cronbach's alpha coefficient was calculated for various items and that of total is displayed in the table 3 below.

Table 3. Questionnaire's reliability

\begin{tabular}{|c|c|}
\hline No of Items & Cronbach's alpha coefficient \\
\hline 37 & $79 \%$ \\
\hline
\end{tabular}

As can be seen in Table 3, Cronbach's alpha coefficient was calculated at $\alpha=0.79$ indicating an acceptable reliability coefficient.

To conduct the study, after obtaining legal permission, questionnaires were delivered in person and with successive pursuing, 166 questionnaires were collected and analyzed 
statistically.

\section{Findings}

In analyzing the data obtained from this research, in order to compare the experimental and theoretical means, a single-group T test was employed and the results displayed as follows:

\section{Hypothesis 1: Tehran's tour guides training courses in terms of learners' reaction have been effective.}

As it can be seen in table 4, this hypothesis has been approved at $99 \%$ confidence and $\alpha$ $=0.01$ level and 164 degree of freedom and $t=4.13$. The average attitude and reaction of the learners (3.19) is higher than the theoretical mean (3). In fact, learners' attitude after taking the course has improved significantly.

Table 4. Single-group T test

\begin{tabular}{|c|c|c|c|c|c|c|}
\hline & \multicolumn{6}{|c|}{ Test value $=3$} \\
\hline & & & & & \multicolumn{2}{|c|}{$\begin{array}{l}\text { 95\% Confidence Interval of the } \\
\text { Difference }\end{array}$} \\
\hline & $\mathrm{t}$ & $\mathrm{df}$ & Sig.(2-tailed) & $\begin{array}{l}\text { Mean } \\
\text { Difference }\end{array}$ & Lower & Upper \\
\hline $\begin{array}{l}\text { REACTION } \\
\text { (ATTITUDE) }\end{array}$ & 4.130 & 165 & .000 & .19231 & .1000 & .2846 \\
\hline
\end{tabular}

Sub-Hypothesis 2: Tour guides training courses in the city of Tehran have been effective in terms of level of learners 'development.

As it can be seen in tables 5 and 6 , this hypothesis is approved at $99 \%$ confidence level and $\alpha=$ 0.01 and 164 degree of freedom and $t=-20.41$. The learning mean rate before training (2.17) and the learning mean after training (3.49) were significantly different, in other words, the difference between learners' learning level before and after taking training courses was significantly meaningful.

Table 5. Paired samples tests

\begin{tabular}{|c|c|c|r|r|}
\hline & Mean & $\mathrm{N}$ & Std. Deviation & Std.Error Mean \\
\hline $\begin{array}{c}\text { LEARNING BEFORE } \\
\text { PROGRAM }\end{array}$ & 2.1733 & 166 & .53276 & .05779 \\
\hline $\begin{array}{c}\text { LEARNING AFTER } \\
\text { PROGRAM }\end{array}$ & 3.4918 & 166 & .45820 & .04970 \\
\hline
\end{tabular}

Table 6. Paired samples test

\begin{tabular}{|c|c|c|c|}
\hline & T & Df & Sig. (2-tailed) \\
\hline LEARNING BEFORE AND AFTER PROGRAM & -20.411 & 164 & .000 \\
\hline
\end{tabular}

Sub-Hypothesis 3: From the learners' perspective, tour guides training program in Tehran have been effective in terms of changing the trainees' behavior.

As it can be seen in Table 7, this hypothesis at 99\% confidence level and $\alpha=0.01$ and164 degree of freedom and $t=10.00$ is approved. Changing behavior mean from the perspective 
of learners (3.54) is higher than the theoretical mean (3) and this illustrates that the trainees' professional behavior in taking the courses has been improved meaningfully.

Table 7. Single-group T test

\begin{tabular}{|c|c|c|c|c|c|c|}
\hline & \multicolumn{6}{|c|}{ Test Value $=3$} \\
\hline & & & & & $95 \%$ Con & al of the \\
\hline & $\mathrm{T}$ & df & Sig.(2-tailed) & $\begin{array}{c}\text { Mean } \\
\text { difference }\end{array}$ & Lower & Upper \\
\hline $\begin{array}{l}\text { BEHAVIOR } \\
\text { CHANGING }\end{array}$ & 10.000 & 165 & .000 & .54167 & .4343 & .6490 \\
\hline
\end{tabular}

Sub Hypothesis 4: From the perspective of employers, the training program has recorded effective concerning changes in the behavior of the trainees.

As it can be seen in table 8, this hypothesis is approved at the $95 \%$ confidence level and $\alpha$ $=0.05$ and 31 degree of freedom and $t=2.12$. The mean of changing behavior from the perspective of employers (3.33) is higher than the theoretical mean (3). In fact, from the perspective of employers, tour leaders' changing behavior during the course has been improved significantly.

Table 8. One-sample test

\begin{tabular}{|l|c|c|c|c|c|c|}
\hline & \multicolumn{5}{|c|}{ Test Value=3 } \\
\hline & \multicolumn{3}{|c|}{} & 95\% Confidence Interval of the Difference \\
\hline & $\mathrm{t}$ & $\mathrm{df}$ & Sig.(2-tailed) & Mean Difference & Lower & Upper \\
\hline BEHAVIOR CHANGING & 2.123 & 31 & .042 & .33333 & .0132 & .6535 \\
\hline
\end{tabular}

Sub Hypothesis 5: From the perspective of employers, tour guides training courses have been effective in Tehran in terms of achieving the goals.

As shown in table 9; this hypothesis then was not approved. This indicates that there is not a meaningful difference between the theoretical average (3) and results (achieving goals) from the perspective of employers (28.3).

Table 9. One- sample test

\begin{tabular}{|l|c|c|c|c|c|c|}
\hline & \multicolumn{5}{|c|}{ Test Value=3 } \\
\hline & \multicolumn{3}{|c|}{ 95\% Confidence Interval of the Difference } \\
\hline & $\mathrm{t}$ & $\mathrm{df}$ & Sig.(2-tailed) & Mean Difference & Lower & Upper \\
\hline RESULTS & 1.844 & 31 & .075 & .28125 & -.0298 & .5923 \\
\hline
\end{tabular}

The main hypothesis of the study: Tour guides training courses have been effective in Tehran.

Out of 5 hypotheses retrieved from the main hypotheses of the study, the acquired means of 4 hypotheses were significantly higher than the theoretical mean which revealed the general effectiveness of the tour guides training programs in Tehran city. The difference in hypothesis number five, which indicated the significant difference between the mean observed and the theoretical mean, was negligible. In other words, with $95 \%$ confidence one can say tour guides training program can be as effective. 


\section{Discussions and Conclusion}

According to the findings of the first research question, the single-group $t$ test results illustrated that, institutions organizing training courses for tour guides in Tehran had been successful in terms of creating positive attitudes and reaction in learners. The findings related to this section of the study indicated that, the expectations of the participants in these classes, who were indeed perceived as incoming tour guides, had been met in an acceptable level.

Increasing the specialized knowledge of the learners, professors and their teaching methods, the relevant and applicable periods; teaching aids, curriculum, and course content play crucial roles in creating positive attitude among the learners and promote learners' satisfaction.

In connection with the findings of the second research question, correlated groups $t$ test results indicated that participants had satisfactory progress in their learning. They had acknowledged that the level of learning before and after the program had increased. Skills, techniques, and a set of knowledge as archeology, culture, art, architecture, geography, and ecotourism and the specialized foreign languages are among those items that had been approved by learners in line with acquiring the subjects and learning progress. In connection with the findings of the third research question, single t-test results displayed that, taking the above mentioned courses had led to learners' professional behavior changing from the participants' point of view. The learners significantly had confirmed that, after accomplishing the course and beginning their professional career in this regard, they would be capable to institutionalize and apply their special knowledge of tourism or conveying the knowledge to others. They also asserted that, they were completely aware of their level of knowledge, skills, and professional behavior changing.

Regarding the findings of the forth research question, the single-group $t$-test results showed that from the perspective of employers, which in the present study consisted of directing managers and technical managers of travel agencies, taking the courses had led to changes in the professional behavior of tour guides who had been trained. In other words, the directors confirmed that the trained tour guides expressed significantly different professional behaviors compared to those who had not taken the training courses.

Considering the findings of the fifth research question, the single-group $t$ - test indicated that from the perspective of the employers who had hired the trained tour guides, although the provided training courses had been effective in tourism training centers, the training programs had not led to achieve the goals of respective organization and thereby costs reduction, service quality enhancement, complaints reduction, standards evolvement, and increasing customer loyalty have not been met yet.

Tour guides, as one of the main components of the tourism industry cannot be effective in performing their duties, unless, they enjoy the specialized training and necessary skills and capabilities to achieve highest development possible in their career. Now days, tour guides training programs in Iran are being executed by private institutions and only under the supervision of the Tourism Department of the Cultural Heritage, Tourism and Handicrafts Organization. Such programs have recorded a -2 decade history in Iran, meanwhile, since the 
beginning of tourism activities and training no evaluation or study has been run on the effectiveness or lack of effectiveness of these activities. The present study was an attempt towards the issue and the research findings proved that the training courses have proved effective as the learners thereof have expressed positive attitude and reaction towards the program and are satisfied with the presented courses and certainly they have confirmed their professional behavior changing.

The managers of travel agencies also find such training courses necessary and helpful and reaffirm the programs' implementation to creating professional behavior in novice tour leaders. Certainly one of the reasons for this success must be searched in private management centers that perform in a competitive atmosphere. Further strengthening these centers by providing facilities and comprehensive support can play an important role in improving country's tour guides training. The managers' claims in lack of effectiveness of such training courses concerning costs reduction, service quality enhancement, complaints reduction from tourists, standards evolvement, and increasing customer loyalty are among those conceivable issues which can be addressed in upcoming researches. While, training centers in charge of organizing training courses on the one hand, and planners and government policymakers on the other hand have been successful in creating positive attitudes and presenting helpful and effective educations and also creating professional behaviors, it seems that, practical knowledge, proficiency and experiments of travel agency and technical managers as the beneficiaries of the program should be more efficiently considered and exploited.

\section{References}

Abasian A. (2006). Effectiveness of Educational Courses in Iran Khodro Company based on Krick Patrick Model, Master Thesis, Tarbiat Moalem University.

Al-Ajlouni M., Athamneh S. \& Jaradat A. (2010). Methods of Evaluation: Training Techniques, International Research Journal of Finance and Economics, 37.

Bazargan A. (1983). Evaluation of Education and its Implementation in Literacy, University Publication Center, Tehran, Iran.

Mohamadkhani K. (2008). Role of Tourist Guides in Cultural Tourists' Satisfaction: Emotionally Intelligent Tourist Guides, Journal of Cultural Management, 2(2), 113-124.

Prakash M. \& Chowdhary N. (2010). What Are We Training Tour Guides For? (India), Turizma, 14(2), 53-65.

Soltani I. (2003). Educational Effectiveness in Organizations, Tadbir Journal, Industrial Management Organization, 12(117,118).

WTO, (2011). World Tourism Barometer, vol. 9, Interim update.

Ya-Hui Elegance Chang, Reio T., \& Smith D. (2010). An Emprical Study of Krick Patrick's Evaluation Model in the Hospitality Industry, Florida International University, Digital Commons, PhD Dissertation. 


\section{Copyright Disclaimer}

Copyright reserved by the author(s).

This article is an open-access article distributed under the terms and conditions of the Creative Commons Attribution license (http://creativecommons.org/licenses/by/3.0/). 